Research Article

\title{
Effects of Instructional Activities Based on Multiple Intelligences Theory on Academic Achievement of Omani Students with Dyscalculia
}

\author{
Suhail Mahmoud AL-ZOUBI ${ }^{1} \&$ Fatma Ali AL-ADAWI $^{2}$ \\ Received: 20 January 2019 \\ Accepted: 11 March 2019
}

\begin{abstract}
The present study is a quantitative research which aims to identify the effects of instructional activities based on Multiple Intelligences Theory (MIT) on academic achievement of the Omani students with dyscalculia (OSD). The sample consisted of 14 male and female students in third and fourth grades enrolled in the resource room at Al-Ahed Primary School, Sultanate of Oman. The sample was randomly distributed to control and experimental groups each group included 7 students. The mathematics test (MT) was applied to both groups as pretest and posttest. The students in the experimental group were enrolled in instructional activities based on MIT at resource room for ten weeks, while the students in the control group were received their individual instruction at resource room at the same period. The results indicated that there were statistically significant differences between the performance of the two groups on post-MT in favour of the OSD in the experimental group.
\end{abstract}

\section{Keywords}

academic achievement, dyscalculia, instructional activities, MIT

\section{To cite this article:}

Al-Zoubi, S. \& Al-Adawi. F. (2019). Effects of instructional activities based on Multiple Intelligences Theory on academic achievement of Omani students with dyscalculia. Journal for the Education of Gifted Young Scientists, 7(1), 1-25. DOI: http://dx.doi.org/10.17478/jegys.515102

\footnotetext{
1 Department of Psychology, Sultan Qaboos University, Alkhoud 123, Sultanate of Oman. E-mail: smalzoubi@squ.edu.om

${ }^{2}$ Ministry of Education, Sultanate of Oman. E-mail: fatma.adwi@moe.om
} 


\section{Introduction}

Intelligence has got a special place of the experts in the educational and psychological sciences. Their research dealt with individual differences and mental abilities that led to the development of the movement of psychological and educational measurement. Their research concluded that Intelligence Quotient (IQ) is a general ability of academic achievement, professional success, creativity and adaptation to the natural and social environment. In the previous century, intelligence was seen as a general mental ability possessed by individuals through a score in IQ tests. Furthermore, intelligence is one of the most prominent activities of the human brain. In his Two-Factor Theory of Intelligence, Spearman emphasized that the intelligence consists of a general factor that includes each individual's performance and a qualitative factor that has an impact on special mental abilities of the individual (Weiten, 2013). In contrast, Thurston in Group Factor Theory stated that the individual possesses primary mental abilities that operate independently of spatial, verbal, numerical, cognitive, memory, and reading abilities (Helmbold, Rammsayer \& Altenmüller, 2005). Therefore, intelligence is the investment of these mental abilities in solving problems (Kovalik \& Olsen, 2007).

Thus, Thurston's findings have opened the door for cognitive psychologists to explore the multiple abilities possessed by individuals, especially Howard Gardner who founded the MIT. The MIT has received extensive discussion among psychologists and one of the most controversial issues of the 21st century (Aborn, 2006). Gardner emphasized that each individual has a group of innate intelligences that patterns concentrated in the parts of the brain (AlZyoud \& Nemrawi, 2015; Shoqeirat \& Alswilmi, 2012). Accordingly, everyone has different degrees of one or more of intelligences (Kahraman \& Bedük, 2016). The individual differs in their abilities and interests and this requires diversity in their learning methods. Therefore, everyone can develop his/her intelligence to the highest level by providing education, encouragement and reinforcement (Armstrong, 2018).

Thus, the MIT contributed to rethinking of intelligence definition, which interprets intelligence through genetic or environmental factors, the MIT came to combine these two factors (Calik \& Birgili, 2013). The MIT has had direct effects in the teaching and learning processes by focusing on creative and productive solution to the problems, and has encouraged teachers to understand students' abilities by selecting the appropriate methods that suit them and raise their concerns. According to the MIT, the individual has one or multiple patterns of the following intelligences: Verbal-Linguistic Intelligence, Logical-Mathematical Intelligence, Visual-Spatial Intelligence, Kinesthetic Intelligence, Musical Intelligence, Intrapersonal Intelligence, Social Intelligence, 
Natural Intelligence, Existence Intelligence, and Spiritual Intelligence (Ambusaidi, 2009; Gouws, 2007; Al-Zyoud \& Nemrawi, 2015; Mahmoud \& Almaharmah, 2014).

The MIT is one of the most prominent cognitive theories that revolutionized in the teaching and learning process and taking into account of individual differences among students (Saban, 2011). The MIT is a contemporary method of teaching children because it provides teachers with an active vision of teaching practices and educational and behavioural approaches capable of taking into account for individual differences between the learners. The MIT contributes to the development of intellectual and creative abilities according to a comprehensive educational vision and its role in preparing learners to meet the requirements of the present century. Therefore, teacher's investment of dominant intelligence patterns from the early childhood will bring benefits to the community and those children (Dolu \& Urek, 2014). The educational value of the MIT emerges through teaching and curriculum development. The peers in the class are different in their personality and patterns of dominant intelligence. Thus, the teacher must be aware of these differences by using teaching methods that are appropriate to the students' dominant patterns of intelligence (Ambusaidi, 2009). The MIT has received interest from teachers and learners because it meets the needs and tendencies of learners and helps teachers to develop strategies based on thinking and problem solving (Al Sulaiti \& Mifdy, 2012).

The academic problems are one of the characteristics of students with learning disabilities (LD). The students with LD may encounter learning problems in reading, writing, and mathematics (Bani Abdel Rahman \& AlZoubi, 2017). Therefore, these problems differ in type, degree and severity among students with LD. The prevalence of LD is estimated at $5.36 \%$ (AlZoubi \& Al-Qahtani, 2015; Lerner \& Johns, 2012), 13\% in the Arab World (Nada, 2009), and $10.5 \%$ in the Sultanate of Oman. The mathematics disabilities are the biggest categories of $\mathrm{LD}$ after reading disabilities. Consequently, $26 \%$ of students with LD have mathematics disabilities, and $50 \%$ of the goals in the individualized education program (IEP) in the USA include instructional objectives in mathematics skills (Lerner \& Johns, 2012). Consequently, LD teachers spend one to third of their time in teaching mathematics skills for students with LD. As a result, it is necessary to address the LD in mathematics by following modern educational programs by using of the MIT. The students with LD have mental abilities above of 85 score on the normal distribution of intelligence, but their achievement level in some academic skills is low. 
The MIT seeks to illustrate the LD through research conducted on the human brain. Research has confirmed that learning is a neurological process that occurs within the brain. (Hakem \& Bekri, 2018). Therefore, LD may be caused by dysfunction in a specific part of the brain, as this result; students with LD acquire and process information in a way that differs from their peers without LD (Silver et al., 2008). According to the Diagnostic and Statistical Manual of Mental Disorders (DSM-5), LD are a neurodevelopmental disorders that appears in the individual as specific learning disorder in reading, writing, and mathematics (Harris, 2014). This means according to MIT there are difficulties in linguistic intelligence or mathematical intelligence or both but other intelligences patterns are working efficiently for students with LD. In other words, LD may occur in any pattern of multiple intelligences. For example, it may occur in the spatial intelligence by the weakness in determining directions or in the kinesthetic intelligence by the weakness in the performance of some physical movements or in the social intelligence through the deficit to master some social skills related to interact with others, understand their feeling sand their gestures as well as to the deficit in social competence or in the intrapersonal intelligence by the low of self-concept or self-esteem or selfefficacy. Consequently, the implementing of the MIT may contribute to improve academic achievement of students with LD (Ashour, 2016).

The students with dyscalculia have a deficit in dealing with numbers and this affects their learning of basic mathematical skills. To reduce the dyscalculia, the teacher who provides remedial instruction to students with dyscalculia should focus on their strengths and patterns of dominant intelligence (McMahon, Rose $\&$ Parks, 2004). Due to educational implementation of MIT are effective, the teacher should plan well for lessons (İnan \& Erkuş, 2017), preparation of activities that invest patterns of dominant intelligence to students with dyscalculia in music, art, drama, sports education and others aspects and the implementation of these activities in their teaching in resource room and general education classroom. In order to achieve an optimal investment for the patterns of dominant intelligence, there must be effective collaboration between LD teacher and teachers of Arabic language, mathematics, sports, musical, drama and artistic education. This collaboration creates a professional integration among teachers and it's positively reflected on improving the learning of students LD (Denig, 2004). Hence, this collaboration based on the MIT will transform the classroom environment from direct instruction based on memorization to a multi-activity instruction that involving students with LD and teachers (Eissa \& Mostafa, 2013). The teacher who gives the lesson rhythmically in or out of class he/she applies the musical intelligence, while the teacher who draws on the blackboard he/she applies visual- spatial intelligence, 
but the teacher who moves in a circular way within the class he/she applies kinesthetic intelligence, whereas the teacher who gives time for interaction between student he/she applies the Intrapersonal intelligence, but the teacher who distributes students into groups he/she applies the social intelligence and the teacher who makes use of school garden in teaching he/she applies natural intelligence.

The LD is one of the special education fields that have got interest from the Omani Ministry of Education (OME). The OME seeks to provide educational services for students with LD by establishing resource room program in general education schools at the various governorates of Sultanate of Oman. This approach by the OME achieves a mainstreaming setting that allows students with LD to receive remedial instruction in the resource room for a period of time and then return to general education class to receive instruction with their peers without LD (Al-Zoubi \& Bani Abdel Rahman, 2016). During field visits to the Omani resource room program, the co-author in current research noted that the students with LD have problems in learning of basic mathematics skills, which is due to a disorder in one or more of the basic psychological processes or to conventional teaching methods or to a teacher's focus on weaknesses of academic skills rather than on the strengths and patterns of dominant intelligence. On the other hand, the instructions of special education supervisors and educational policies of the OME may contribute to the dyscalculia by forcing a learning disability teacher to prepare an IEP to address the deficiencies in the linguistic or mathematical aspect or both without allowing him or her to implement other multiple intelligences in the IEP. So, the current research aimed to identify the effects of instructional activities based on the MIT on the academic achievement of OSD by answering the following hypothesis: There were no statistically significant differences between the mean rank of the control and experimental groups on MT due to instructional activities based on the MIT.

\section{Method}

\section{Research Design}

A Practical Educational Action Research (PEAR) was used. The PEAR is one of the types of educational action research that seeks to find solutions to problems facing the educational field. In this regard, Newton and Burgess (2008) concluded that there are three types of educational action research: emancipatory, practical and knowledge-generating. In the current research, the PEAR was used in Al-Ahed Primary School by divided students with dyscalculia to control and experimental groups. 


\section{Participants}

The participants in current research consisted of 14 students with LD in the third and fourth grades enrolled in the resource room program at Al-Ahed Primary School in Al Batinah South Governorate, Oman. The students' ages ranged from 8 to 10 years. The participants have dyscalculia based on a set of formal and informal scales introduced by OME. The participants were divided into two groups; each group included seven students.The first group was selected as a control group and the second as experimental group by using the simple random sampling method. The distribution of the study sample according to group and gender were presented in Table 1.

Table 1.

Distribution of Sample in terms of Group and Gender

\begin{tabular}{lccc}
\hline Group & Gender & Frequency & Percentage $(\%)$ \\
\hline Control & Male & 4 & 29 \\
& Female & 3 & 21 \\
Experimental & Male & 4 & 29 \\
& Female & 3 & 21 \\
\hline
\end{tabular}

\section{Instruments}

The MT

To develop the MT, the Omani mathematics curriculum for third and fourth grade and the IEP of students in control and experimental groups were reviewed. The first draft of MT consisted of 21 true or false questions. To verify the validity, the MT was reviewed by four experts in special education and curricula at Omani universities and three special education supervisors at OME. Based on their suggestions, the MT questions that received a score of $85 \%$ were included in the test. The final draft of MT consisted of 15 true or false questions. Each correct answer was given one mark and each incorrect answer a zero mark. The MT measure skills which appropriate to level of OSD in third and fourth grade such as reading and writing four-digit numbers, ascending and descending of numbers, place value of numbers, basic mathematical operations and discrimination between greater sign $(>)$ and less sign $(<)$. To measure the reliability, the MT was conducted to a pilot study that consisted of 18 OSD enrolled in the resource room program at a primary school in the Al Batinah South Governorate, Oman. The internal consistency coefficient of MT was 0.85 by using Kuder-Richardson Formula 20. While, the range of difficulty coefficient of MT questions was 0.57-0.69 and the range of coefficient of discrimination was $0.44-0.58$. 


\section{Instructional Activities Based on MIT}

To identify patterns of dominant intelligences among OSD in the experimental group, The Multiple Intelligences Checklist has been used. The checklist was developed by Nofal (2010) which was consisted of 80 items distributed to eight types of intelligences related to Linguistic Intelligence, Mathematical Intelligence, Spatial Intelligence, Musical Intelligence, Kinesthetic Intelligence, Social Intelligence, Intrapersonal Intelligence, and Natural Intelligence. The implementation of the checklist showed that there was a similarity in the patterns of dominant intelligences among OSD in the experimental group. Accordingly, a set of educational strategies and instructional activities based on these eight intelligences have been applied. Thus, instructional activities are applied based on dominant intelligence in the majority of OSD in the experimental group. These activities are invested in addressing the dyscalculia. In order to optimize the implementation of eight multiple intelligences based on instructional activities in the teaching of mathematics skills, the followings have been taken into account:

$>$ Gradual from easy to hard and tangible to abstract in order to activate the Kinaesthetic Intelligence and Spatial Intelligence.

$>$ Focusing on basic mathematical concepts to stimulate Mathematical Intelligence.

$>$ Using of educational songs to activate the Musical Intelligence and Linguistic Intelligence.

$>$ Linking mathematical rules on the classroom environment to activate the Social Intelligence and Intrapersonal Intelligence.

\section{Procedures}

$>$ Obtain an approval letter from the principal of Al-Ahed Primary School to conduct this research.

$>$ Obtain approval from the parents of OSD to apply multiple intelligences on their children in the experimental group.

$>14$ OSD were selected from the third and fourth grades at Al-Ahed Primary School. These students were randomly distributed to a control group and experimental groups and each group included 7 students.

$>$ The MT was developed after reviewed the strengths and weaknesses included in the IEP for each student in the control and experimental groups. The MT consisted of 15 true or false questions.

$>$ The MT was applied to OSD in the control and experimental groups as a pretest. The first author in the current research was applied the MT on the students because she is a LD teacher at Al-Ahed Primary School. 
$>$ The students in the control group were enrolled in resource room program at Al-Ahed Primary School in the first semester 2017/2018 and received solo-teaching in mathematics by the first author. Therefore, the 10 weeks was duration for the implementation this research on the students in the control group with one lesson per day starting from 9 to 9:4 am, and 5 lessons per week.

$>$ The students in the experimental group were enrolled in resource room program at Al-Ahed Primary School in the first semester 2017/2018 and received teaching in mathematics according to instructional activities based on the MIT by the first author. Therefore, the 10 weeks was duration for the implementation this research on the students in experimental group with one lesson per day starting from 11 to 11:45 am, and 5 lessons per week.

$>$ After implementing of current research, the first author was applied the MT on the students in the experimental and control as a posttest.

\section{Results}

Results related to research hypothesis: There were no statistically significant differences between the mean rank of the control and experimental groups on MT due to effects of MIT? To answer this hypothesis, descriptive statistics was used to identify the performance of students on the pre-MT and post-MT. Mean and standard deviation were presented in Table 2.

Table 2.

Descriptive Statistics

\begin{tabular}{lcccc}
\hline Group & \multicolumn{2}{c}{ Control } & \multicolumn{2}{c}{ Experimental } \\
\hline Measure & Pre-MT & Post-MT & Pre-MT & Post-MT \\
Number & 7 & 7 & 7 & 7 \\
Mean & 4.71 & 6.42 & 5.14 & 10.57 \\
SD & 1.38 & 1.39 & 1.34 & 1.51 \\
\hline
\end{tabular}

Table 2 shows there were differences in the mean of the control and experimental groups on the pre-MT and post-MT. In order to determine the statistical significance of these differences, the Mann-Whitney test was used and Table 3 shows the results. 


\section{Table 3.}

Results of the Mann Whitney Test

\begin{tabular}{lcccccc}
\hline Measure & Group & $\begin{array}{c}\text { Mean } \\
\text { Rank }\end{array}$ & $\begin{array}{c}\text { Sum of } \\
\text { Ranks }\end{array}$ & Z & P & $\eta^{2}$ \\
\hline Pre-MT & Control & 6.79 & 47.50 & -.670 & .503 & \\
& Experimental & 8.21 & 57.50 & & & 0.66 \\
Post- & Control & 4.14 & 29.00 & -3.02 & .002 & \\
MT & Experimental & 10.86 & 76.00 & & & \\
\hline
\end{tabular}

Table 3 shows that there were no statistically significant differences between the mean rank of the two groups on the pre-MT. The result indicated the equivalence between the control and experimental groups on the pre-MT $(Z=-$ $.670, \mathrm{p}=.503)$. Moreover, Table 2 also shows that there were statistically significant differences between the mean rank of the two groups on the postMT $(Z=-3.02, p=.002, \eta 2=0.66)$. These differences were in favour to the students in experimental group. Furthermore, the eta squared $(\eta 2=0.66)$ showed high effect size of the instructional activities based on the MIT on improving academic achievement of the students in the experimental group.

\section{Discussion}

The results showed the effectiveness of instructional activities based on the MIT on improving the academic achievement of students in the experimental group. This result confirms that the teaching methods and instructional activities were suitable for the eight intelligences patterns of students in the experimental group. Thus, traditional teaching methods depend only on cognitive abilities but the teaching methods based on the MIT depend on cognitive and non-cognitive abilities which contribute to the diversity in sources of information reception among students with LD. Therefore, the use of unconventional methods and strategies with students in the experimental group contributes to improve their academic achievement and motivation towards learning. Al-Qamash (2012) emphasized the educational curricula focusing on linguistic intelligence and mathematical intelligence which are the source of academic problems for students with LD and these curricula neglect other intelligences. In this regard, the OME and teachers of LD should conduct a comprehensive review of the educational curricula and the IEP for students with LD by the use of teaching methods that stimulate students' learning motivation, provide them with opportunities for thinking and creativity, and gain them ability to learn.

The MIT has become a contemporary method of exploring learning and teaching for each student as well as its contribution to curriculum development 
and improving student assessment methods. Thus, the MIT has revolutionized in the educational practices, changed teachers' perceptions of their students, and explained the appropriate methods to deal with them according to their abilities and their intelligence patterns. The MIT in the current research did not provide a new trend to recognize the nature of intelligence but presented instructional activities which contributed to discover learning styles and patterns of dominant intelligence among OSD in the experimental group. The MIT challenged the traditional term of intelligence, which recognized only in one of intelligence pattern that can rise or fall during growth stages.

Based on neuropsychology, the MIT is based on functions of the cerebral cortex. This means that each pattern of multiple intelligences dominates in a specific area in the brain. Accordingly, the implementation of instructional activities and strategies based on the MIT contributes to stimulate the lobes in the cerebral cortex in the right and left hemisphere according to the activity used for each intelligences pattern which targeted in the teaching process. Therefore, the instructional activities based on the MIT in the current research contributed to motivate of linguistic intelligence in the left brain by read students the numbers and instructional activities based on brainstorming to solve some arithmetic. These activities also contributed to the stimulation of students' personal intelligence through the analysis of ideas and the motivation of mathematical intelligence through logical thinking. The role of these instructional activities was not limited to the left brain, but also stimulated the kinesthetic, social, musical and spatial intelligence in the right brain. Thus, the instructional activities took into consideration of intelligence patterns for each student in the experimental group and contributed to stimulating most parts of the brain, which positively affected on the students' achievement in the experimental group compared with the students in the control group who studied by traditional teaching method based on linguistic intelligence only.

The awareness of the OSD in the experimental group with their multiple intelligence patterns contributed to the enhancement of their academic achievement in mathematics and helped the first author to invest these intelligences in addressing the deficit in language and mathematics aspects. Consequently, a student with kinesthetic intelligence was taught mathematics skills by activities based on the investment of muscles and tactility. The student with spatial intelligence was taught by activities based on observation and the distinction between geometric shapes, volumes and surveying. The student with mathematical intelligence was taught through activities based on logical thinking. While, the student with social intelligence was taught through activities based on social skills. In addition, the student with musical intelligence was taught through activities based on educational songs. In this regard, 
Dahash (2010) indicated the effectiveness of an educational program based on the MIT on improving mathematical thinking. Batdi (2017) concluded the effectiveness of the MIT on the academic achievement. While, Al-Zyoud and Nemrawi (2015) stressed the effect of a teaching strategy based on MIT on improving the basic arithmetic operations of students with mathematical LD. Hakem and Bekri, (2018) pointed to the effectiveness of an educational program based on MIT to address LD on improving the basic arithmetic operations of students with mathematical LD.

The instructional activities presented in the current research were harmony with each pattern of intelligences, and this gave each student in the experimental group opportunity to acquire knowledge and learning through multiple approaches to meet his or her potential and abilities. The variety of information provided by the first author has helped students to reduce the boredom and break the routine that have been accustomed during their traditional teaching in the resource room program and this raises the students' motivation to learn and enthusiasm by the new teaching method and love of mathematics. Therefore, the instructional activities based on the MIT achieve contemporary trends in special education, which demands that no child left behind. The core of the MIT achieves these trends by focused on individual learning according to the dominant intelligence pattern for each student in the experimental group. In other words, the method of providing instructional activities, consider the learner as core of learning and teaching process and teaching method of the first author has had an impact on improving the mathematics skills among OSD in the experimental group. The high level of effect size indicates that the MIT has not only contributed on improving mathematical skills, but also came to identify other patterns of intelligence among OSD in the experimental group which may be neglected according to traditional teaching methods used with OSD in the control group.

These results lead to reject of null hypothesis and acceptance of alternative hypothesis because there were statistical differences between the mean rank of the control and experimental groups on the post-MT. In this regard, Hijazi and Al-Mingash (2017) showed the effectiveness of instructional activities based on a set of multiple intelligences on improving the reading skills of students with LD. Ashour (2016) concluded that the educational program based on the MIT contributed to improve mathematics skills and logical intelligence among students with LD. Elkeshky and Sindi (2016) revealed that the mathematical and kinesthetic intelligence are the most common patterns of multiple intelligences among students with LD. These results lead to rethink of learning methods used with OSD that address only deficits in the linguistic and mathematical aspects. 
In other words, future education of students with LD in Oman should be focused on the core of the MIT. The MIT will enhance broad perspectives to curricula and the IEP that contributes to stimulating the minds of students with LD. The diversity of multiple intelligence patterns among students require from the OME to find approaches of teaching and learning that reveal their multiple intelligences. This diversity of intelligence patterns contribute to the variety of the society culture by opening the way for each pattern to appear in a field that benefits the advancement of human societies.

\section{Conclusion}

The results indicated positive effects of instructional activities based on the MIT on improving the mathematics skills among OSD. According to these results, the researchers recommend to rethink of the IEP to include instructional activities based on MIT, holding training workshops for LD teachers and conducting research in other governorates in Oman. The small size of sample and the action research methodology are limitations to reduce the generalization the results to all OSD in the Omani primary schools.

\section{Disclosure and Conflicts of Interest}

The authors declared no potential conflicts of interest with respect to the research, authorship, and/or publication of this article. This research is original work and does not contain any libelous or unlawful statements or infringe on the rights or privacy of others or contain material or instructions that might cause harm or injury.

\section{Acknowledgments}

The researchers would like to extend their gratitude to students with dyscalculia and the principal of Al-Ahed Primary School to facilitate conduct of this research. Special thanks go to Dr. Samer Al-Zoubi at Department of English in Ajloun National University for reviewing and editing this research.

\section{References}

Aborn, M. (2006). An intelligent use for belief. Education, 127(1), 83-85.

Al Sulaiti, F.,\& Mifdy, K. (2012).The Effect of the strategies of multiple-intelligences and six hats strategies and problem solving in the development of eighth grader's scientific thinking skills in Jordan. Journal of Educational and Psychological Studies, 6(1), 80-98.

Al-Qamash, M. (2012).Multiple intelligences among students with learning disabilities. Journal of Educational and Psychological Studies, 6(2), 59-75.

Al-Zoubi, S., \& Al-Qahtani, M. (2015).The effects of token reinforcement on reducing symptoms of attention deficit hyperactivities disorders among students with learning disabilities. Jordan Journal of Educational Sciences, 11(3), 373-386. 
Al-Zoubi, S., \& Bani Abdel Rahman, M. (2016).Mainstreaming in Kingdom of Saudi Arabia: Obstaclesfacing learning disabilities resource room. Journal of Studies in Education, 6(1), 37-55.

Al-Zyoud, N.,\& Nemrawi, Z. (2015).The efficiency of multiple intelligence theory (MIT) in developing the academic achievement and academic-self of students with mathematical learning disabilities in the areas of addition, subtraction and multiplication. American International Journal of Social Science, 4(2), 171-180.

Ambusaidi, A. (2009). The effect of teaching strategies based on multiple intelligence theory on academic achievement and alternative conceptions in chemistry. Journal of King Saud University - Educational Sciences and Islamic Studies, 21(1), 1-33.

Armstrong, T. (2018). Multiple intelligences in the classroom (4th ed.). Alexandria, VA: ASCD.

Ashour, M. (2016).The relationship between multiple intelligences and academic achievement of students with learning disabilities. Educational and Psychological Studies, (92), 207-242.

Bani Abdel Rahman, M., \& Al-Zoubi, S. (2017).Effects of classwide peer tutoring on word attack skills among students with learning disabilities. European Journal of Special Education Research, 2(5), 88-101.

Batdi, V. (2017). The effect of multiple intelligences on academic achievement: A metaanalytic and thematic study. Educational Sciences: Theory \& Practice, 17, 2057-2092.

Calik, B., \& Birgili, B. (2013). Multiple intelligence theory for gifted education: Criticisms and implications. Journal for the Education of Gifted Young Scientists, 1(2), 112.

Dahash, A. (2010). The effectiveness of an educational program based on multiple intelligences theory on improving mathematical thinking among students in Saudi Arabia. Faculty of Education Journal, 34(2), 225-274.

Denig, S. (2004). Multiple intelligences and learning styles: Two complementary dimensions. Teachers College Record, 106(1), 96-111.

Dolu, G., \& Urek, H. (2014).A study related to the investigation of multiple intelligence profiles of gifted and talented children across Turkey. Journal for the Education of the Young Scientist and Giftedness, 2(2), 58-66.

Eissa, M.,\&Mostafa, A. (2013). Integrating multiple intelligences and learning styles on solving problems, achievement in, and attitudes towards math in six graders with learning disabilities in cooperative groups. International Journal of Psycho-Educational Sciences, 2(2), 32-45.

ELkeshky, M., \& Sindi, L. (2016).Level of multiple intelligence in a sample of pupils with learning disabilities in public primary stage in Jeddah. Journal of Special Education and Rehabilitation, 3(10), 160-162.

Gouws, F. (2007). Teaching and learning through multiple intelligences in the outcomes-based education classroom, Africa Education Review, 4(2), 60-74.

Hakem, O., \& Bekri, A. (2018).The effectiveness of an educational program based on multiple intelligences theory to address learning disabilities in mathematicsamong elementary students. Journal of Educational and Psychological Sciences, 6(1), 102-128.

Harris, J. (2014). New classification for neurodevelopmental disorders in DSM-5. Current Opinion in Psychiatry, 27(2), 95-97.

Helmbold, N., Rammsayer, T., \& Altenmüller, E. (2005). Differences in primary mental abilities between musicians and nonmusicians. Journal of Individual Differences, 26(2), 74-85. 
Hijazi, A., \& Al-Mingash, A. (2017). The effectiveness of a program based on the multiple intelligences activitiesin the development of reading skills among pupil students with learning disabilities. Saudi Journal of Special Education, (6), 119-161.

İnan, C., \& Erkuş, S. (2017). The effect of mathematical worksheets based on multiple intelligences theory on the academic achievement of the students in the $4^{\text {th }}$ grade primary school. Universal Journal of Educational Research 5, 1372-1377.

Kahraman, S., \& Bedük, S. (2016). Multiple intelligences and perfectionism in middle school gifted students. Journal for the Education of Gifted Young Scientists, 4(2), 1-13.

Kovalik, S., \& Olsen, K. (2007). Exceeding expectations: A user's guide to implementing brain research in the classroom (3rd. ed.). Federal Way, WA: Books for Education.

Lerner, J., \& Johns, B. (2012). Learning disabilities and related mild disabilities. Belmont, CA: Wadsworth Cengage Learning.

Mahmoud, A., \&Almaharmah, L. (2014). The level of multiple intelligences among special education teachers in Jordan. Dirasat: Educational Sciences, 41(1), 115-127.

Mcmahon, S., Rose, D., \& Parks, M. (2004). Multiple intelligences and reading achievement: An Examination of the Teele Inventory of Multiple Intelligences. The Journal of Experimental Education 73(1), 41-52.

Nada, A. (2009). Learning disabilities. Amman, Jordan: AlWaraq Publishing.

Newton, P., \& Burgess, D. (2008).Exploring types of educational action research: Implications for research validity. International Journal of Qualitative Methods, 7(4), 1830.

Nofal, M. (2010).Multiple intelligence in the classroom. Amman, Jordan: Massira for Publishing.

Saban, A. (2011). An evaluation of the teaching activities implemented in the elementary science and technology courses in terms of multiple intelligence theory: a sample from Adana. Educational Sciences: Theory \& Practice, 11(3), 1641-1649.

Shoqeirat, M., \& Alswilmi, A. (2012).The effect of multiple intelligence theory strategies in the achievement of sixth grade students in the science. Journal of Arab Children, 13(52), 47-67.

Silver, C., Ruff, R., Iverson, G., Barth, J., Broshek, D., Bush, S., ... Reynolds, C. (2008). Learning disabilities: The need for neuropsychological evaluation. Archives of Clinical Neuropsychology, 23(2), 217-219.

Weiten, W. (2013). Psychology: Themes and V ariations (9th ed.). Belmont, CA: Wadsworth. 